\title{
Surfactant Modulated Phase Transitions of Liquid Crystals Confined in Electrospun Coaxial Fibers
}

\author{
Kevin T. Dicker ${ }^{\dagger}$, Daniel Ratchford, Riccardo Casalini, Matthew D. Thum $¥$, James H. Wynne, Jeffrey G. \\ Lundin* \\ Chemistry Division, Naval Research Laboratory, 4555 Overlook Avenue SW, Washington, D.C. 20375 \\ †National Research Council Post-Doctoral Research Associate \\ $¥$ American Society for Engineering Education Post-Doctoral Research Associate
}

*Corresponding author. Tel.: (202)767-2529, Email address: jeffrey.lundin@nrl.navy.mil

Figure S1. DSC thermogram overlay of 5CB-PVP fibers containing various surfactants directly compared to neat $5 \mathrm{CB}$.

Figure S2. All DSC thermogram replicates of 5CB-PVP containing various concentrations of Brij ${ }^{\circledR} 93$.

Figure S3. Average fiber diameter of 5CB-PVP fibers with Brij ${ }^{\circledR 93}$ surfactant and no surfactant.

Figure S4. Polarized optical microscopy images of the core flow rate effects on fiber diameter. (A) 5CBPVP fibers without surfactant and (B) withBrij ${ }^{\circledR} 93$ with core flow rates of $0.5,1.0$, and 1.5 $\mathrm{mL} \mathrm{hr}^{-1}$.

Figure S5. The effect of core diameter on fibers containing Brij ${ }^{\circledR C} 10$ (A,D) and Span20 (B,C). DSC thermograms of (A) Brij ${ }^{\circledR C} 10$ and (B) Span20 with core flow rates of $0.5,1.0$ and $1.5 \mathrm{~mL} \mathrm{hr}^{-1}$. Polarized optical microscopy images of 5CB-PVP fibers with (C) Span20 and (D) Brij ${ }^{\circledR C} 10$ with core flow rates of $0.5,1.0$, and $1.5 \mathrm{~mL} \mathrm{hr}^{-1}$.

Figure S6. Molar surfactant concentration (at $1 \mathrm{wt} \%$ ) vs $\mathrm{T}_{\mathrm{N} \rightarrow \mathrm{I}}$.

Figure S7: Cross polarized microscopy of electrospun fibers with a core flow rate of $0.5 \mathrm{~mL} \cdot \mathrm{h}^{-1}(\mathrm{~A})$ and $1.0 \mathrm{ml} . \mathrm{h}^{-1}(\mathrm{C})$. SEM images of electrospun fibers with a core flow rate of with a core flow rate of $0.5 \mathrm{~mL} \cdot \mathrm{h}^{-1}(\mathrm{~B})$ and $1.0 \mathrm{ml} \cdot \mathrm{h}^{-1}(\mathrm{C})$. POM and SEM image scale bars $=25 \mu \mathrm{m}$.

Figure S8: Cross polarized microscopy of electrospun fibers with $1 \mathrm{wt} \%$ Brij ${ }^{\circledR} 93$ and a core flow rate of $0.5 \mathrm{~mL} \cdot \mathrm{h}^{-1}(\mathrm{~A})$ and $1.0 \mathrm{ml} \cdot \mathrm{h}^{-1}(\mathrm{C}) . \mathrm{SEM}$ images of electrospun fibers with a core flow rate of with a core flow rate of $0.5 \mathrm{~mL} \cdot \mathrm{h}^{-1}(\mathrm{~B})$ and $1.0 \mathrm{ml} \cdot \mathrm{h}^{-1}(\mathrm{C})$. POM and SEM image scale bars $=$ $25 \mu \mathrm{m}$.

Figure S9: FIB-SEM of 5CB-PVP electrospun fibers w/o surfactant with a core flow rate of $1.0 \mathrm{ml} \cdot \mathrm{h}^{-1}$. 


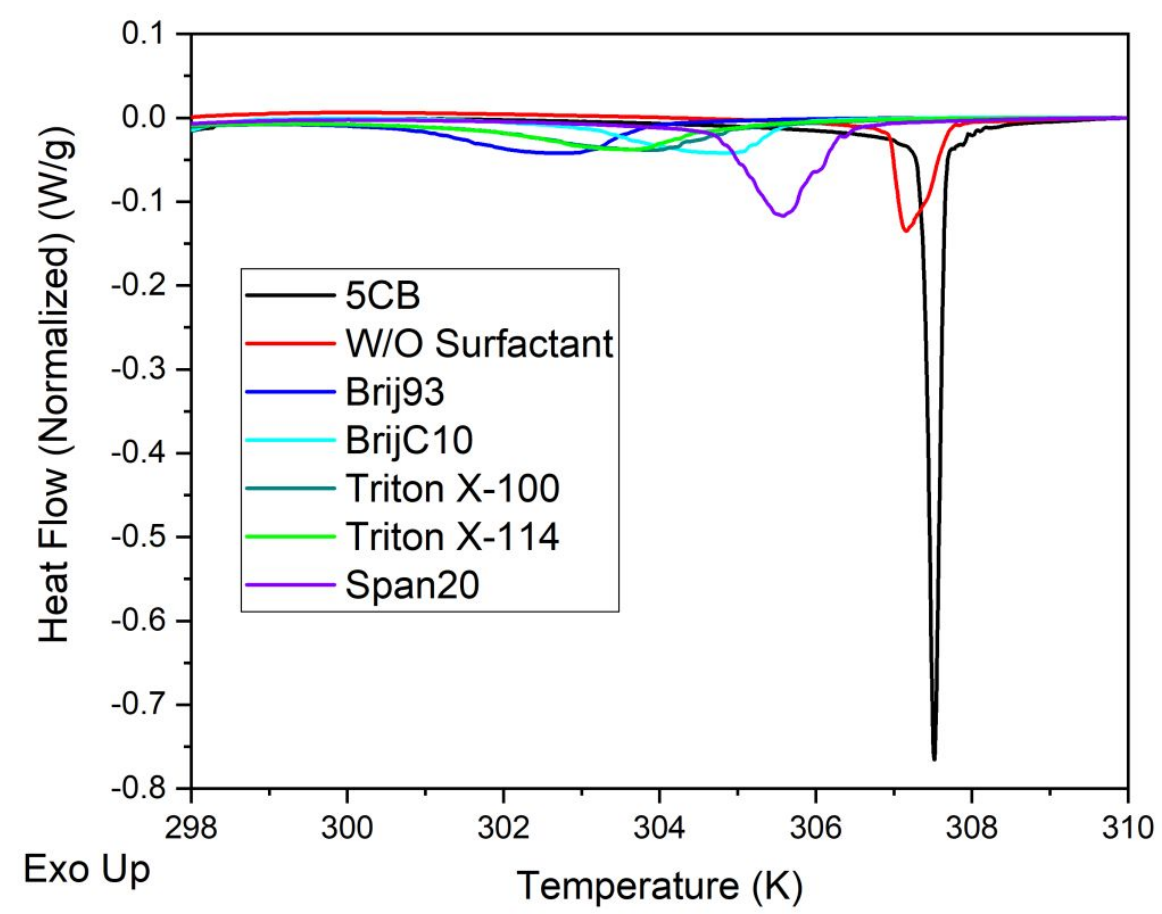

Figure S1. DSC thermogram overlay of 5CB-PVP fibers containing various surfactants directly compared to neat $5 \mathrm{CB}$.

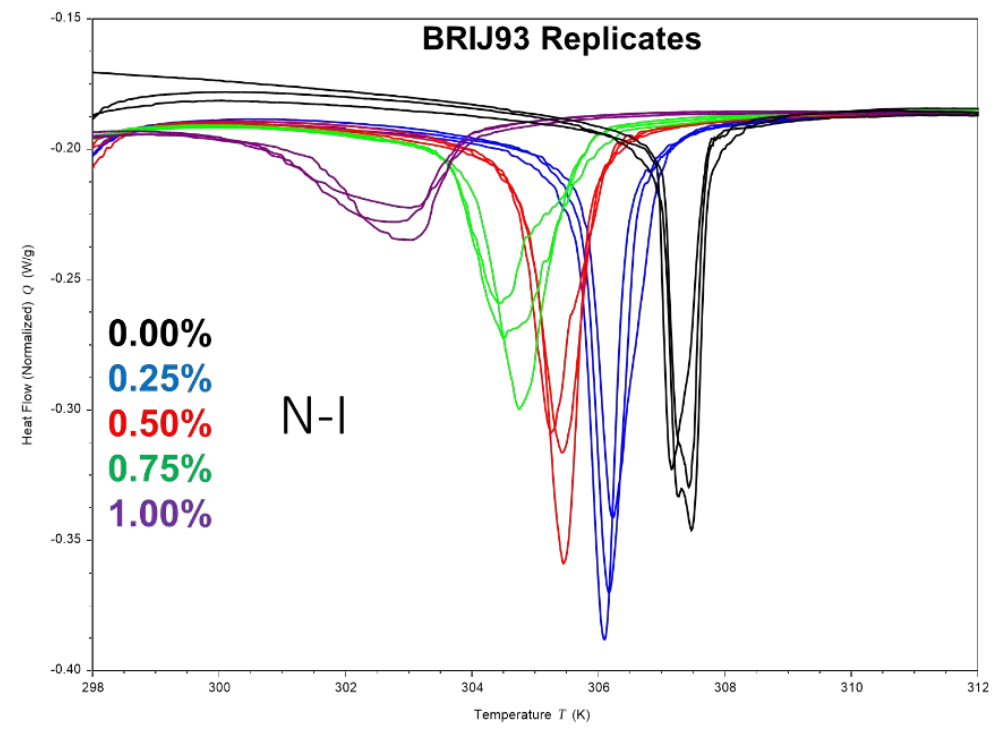

Figure S2. All DSC thermogram replicates of 5CB-PVP containing various concentrations of Brij®93. 


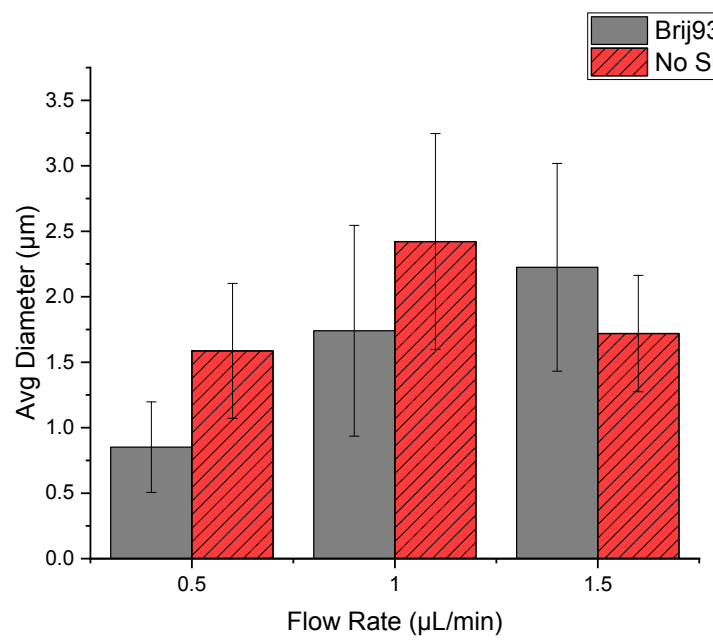

Figure S3. Average fiber diameter of 5CB-PVP fibers with Brij ${ }^{\circledR 93}$ surfactant and no surfactant.
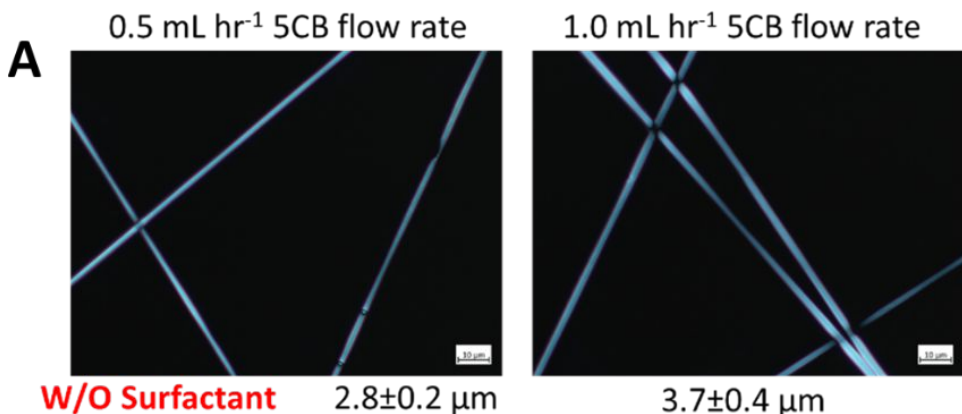

$3.7 \pm 0.4 \mu \mathrm{m}$

B

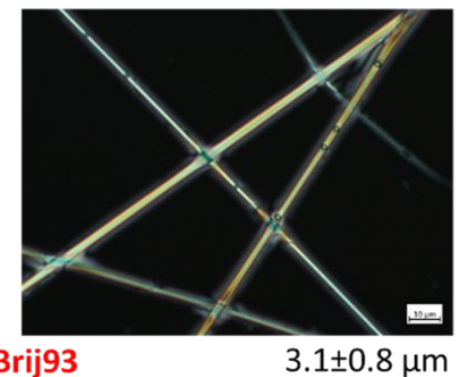

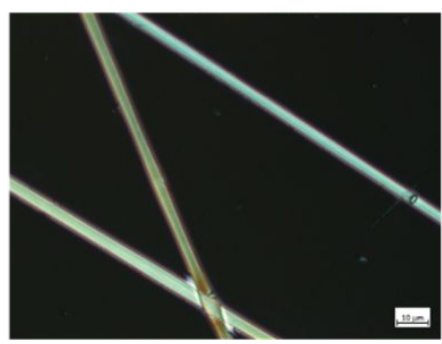

$5.2 \pm 0.6 \mu \mathrm{m}$
$1.5 \mathrm{~mL} \mathrm{hr}^{-1} 5 \mathrm{CB}$ flow rate

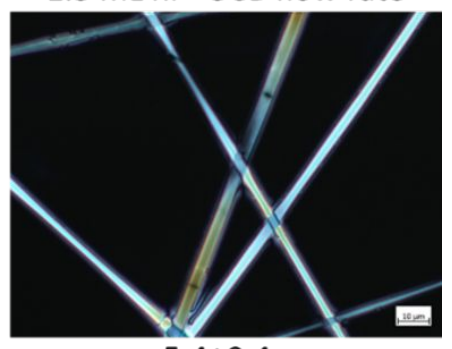

$5.4 \pm 0.4 \mu \mathrm{m}$

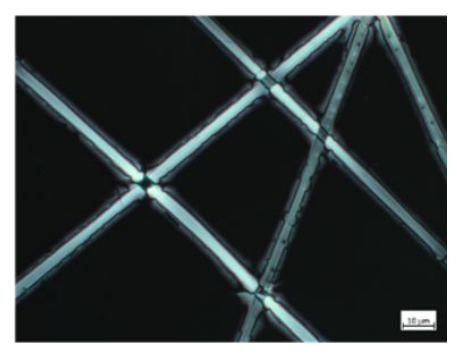

$5.5 \pm 0.2 \mu \mathrm{m}$

Figure S4. Polarized optical microscopy images of the core flow rate effects on fiber diameter. (A) 5CBPVP fibers without surfactant and (B) with Brij ${ }^{\circledR 9} 93$ with core flow rates of $0.5,1.0$, and $1.5 \mathrm{~mL} \cdot \mathrm{hr}^{-1}$. 

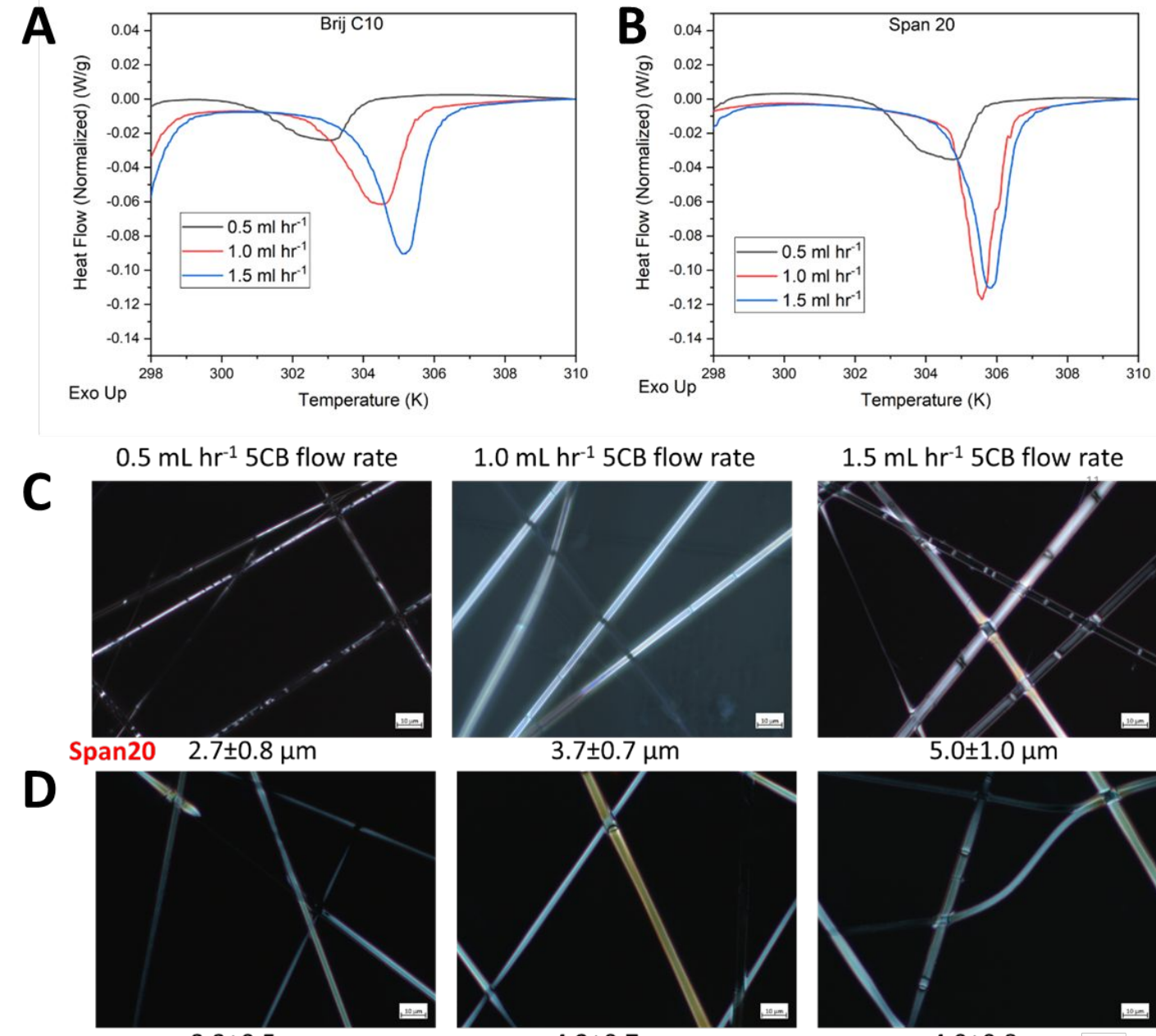

BrijC10 $3.3 \pm 0.5 \mu \mathrm{m}$

$4.2 \pm 0.7 \mu \mathrm{m}$

$1.5 \mathrm{~mL} \mathrm{hr}^{-1} 5 \mathrm{CB}$ flow rate

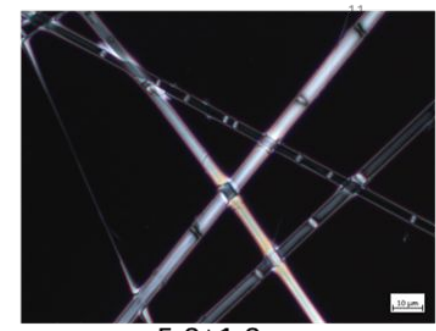

$5.0 \pm 1.0 \mu \mathrm{m}$

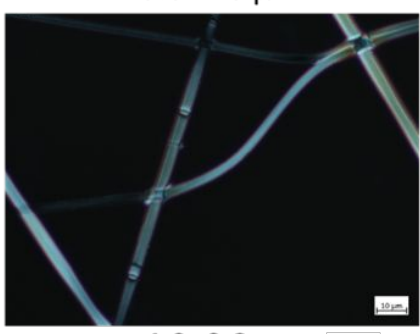

$4.9 \pm 0.8 \mu \mathrm{m}$

Figure S5. The effect of core diameter on fibers containing Brij ${ }^{\circledR C} 10(A, D)$ and Span20 (B,C). DSC thermograms of (A) Brij ${ }^{\circledR C} 10$ and (B) Span20 with core flow rates of $0.5,1.0$ and $1.5 \mathrm{~mL} \cdot \mathrm{hr}^{-1}$. Polarized optical microscopy images of 5CB-PVP fibers with (C) Span20 and (D) Brij®C10 with core flow rates of $0.5,1.0$, and $1.5 \mathrm{~mL} \cdot \mathrm{hr}^{-1}$. 


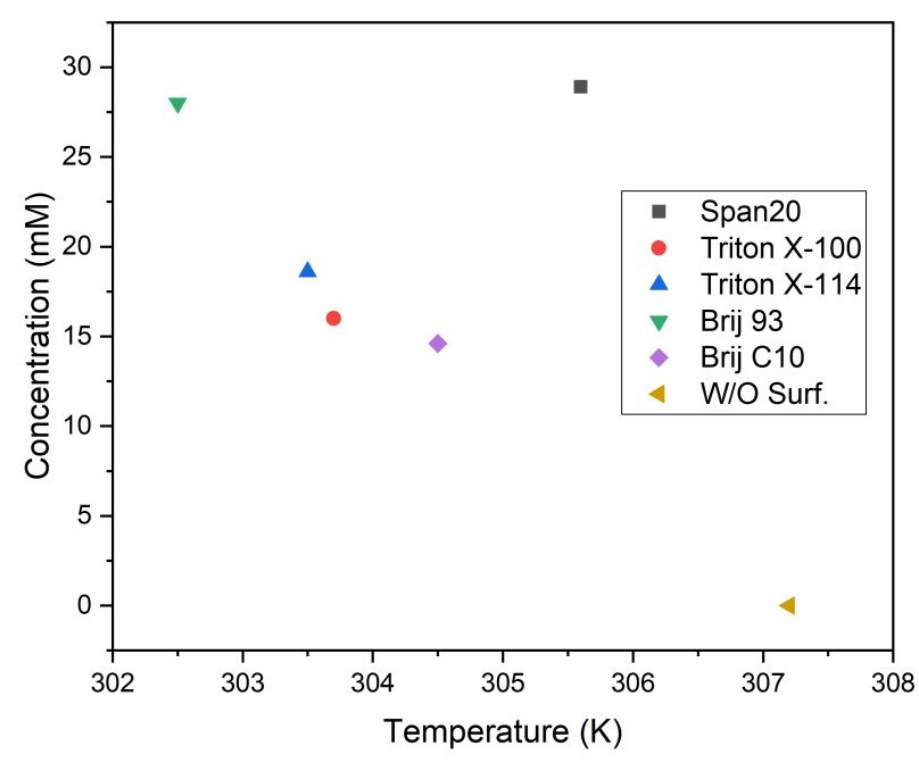

Figure S6. Molar surfactant concentration (at $1 \mathrm{wt} \%$ ) vs $\mathrm{T}_{\mathrm{N} \rightarrow \mathrm{I}}$.
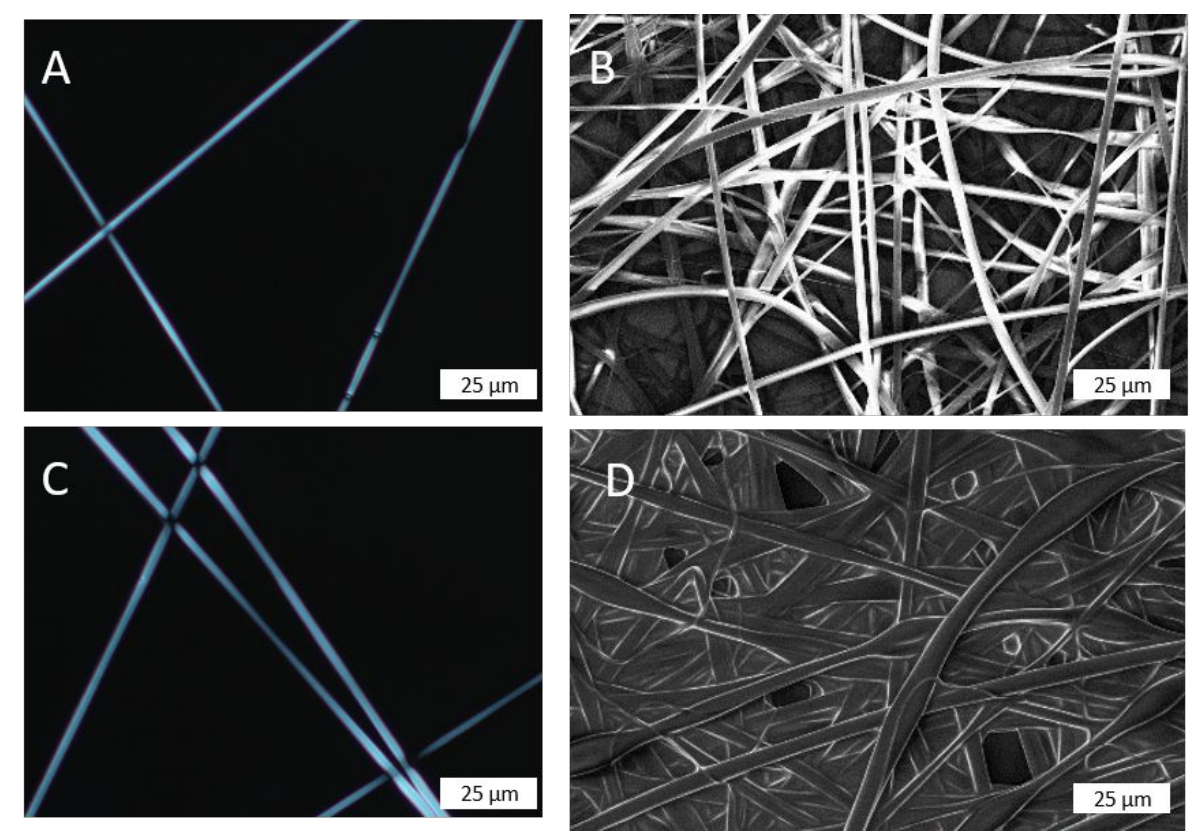

Figure S7: Cross polarized microscopy of electrospun fibers with a core flow rate of $0.5 \mathrm{~mL} \cdot \mathrm{h}^{-1}(\mathrm{~A})$ and $1.0 \mathrm{ml} \cdot \mathrm{h}^{-1}(\mathrm{C})$. SEM images of electrospun fibers with a core flow rate of with a core flow rate of 0.5 $\mathrm{mL} \cdot \mathrm{h}^{-1}(\mathrm{~B})$ and $1.0 \mathrm{ml} \cdot \mathrm{h}^{-1}(\mathrm{C})$. POM and SEM image scale bars $=25 \mu \mathrm{m}$. 

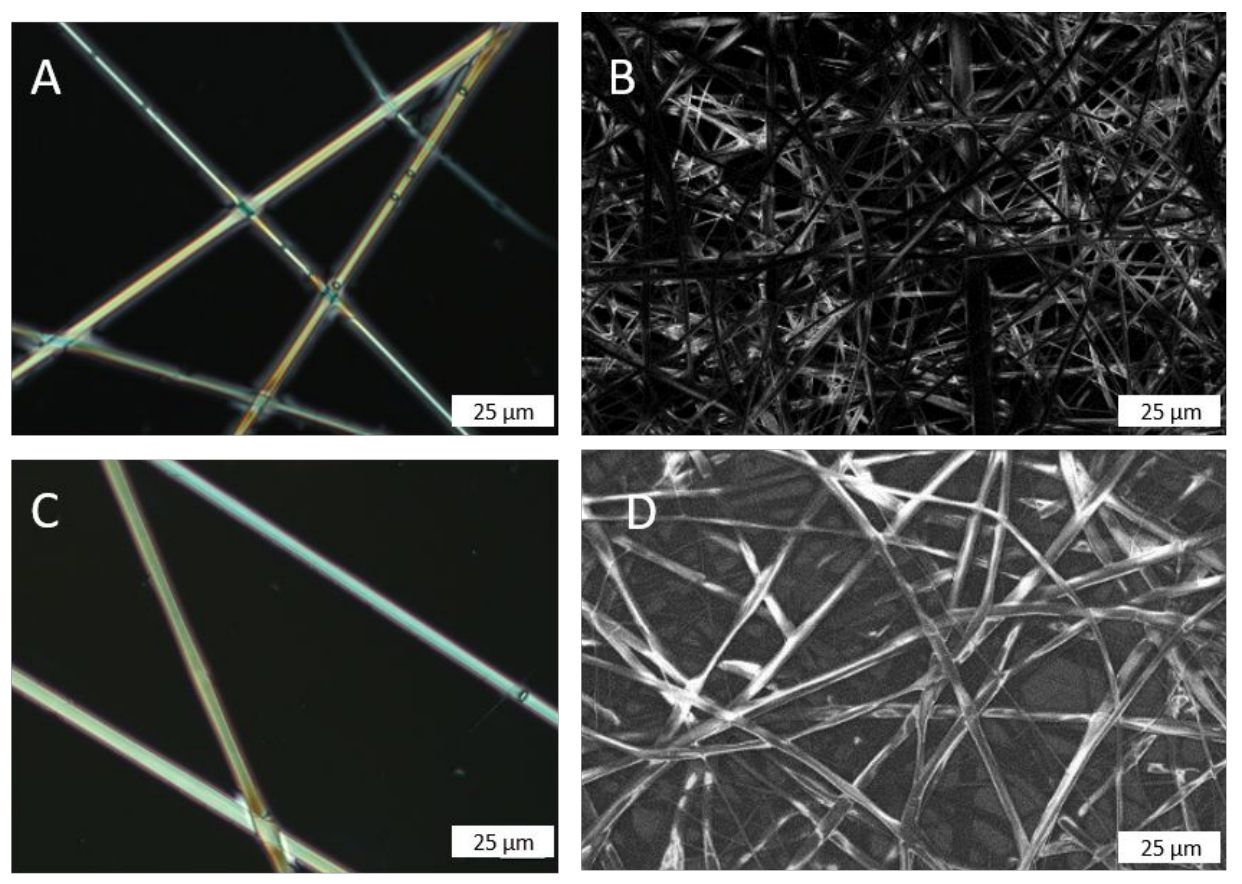

Figure S8: Cross polarized microscopy of electrospun fibers with $1 \mathrm{wt} \%$ Brij ${ }^{\circledR} 93$ and a core flow rate of $0.5 \mathrm{~mL} \cdot \mathrm{h}^{-1}(\mathrm{~A})$ and $1.0 \mathrm{ml} \cdot \mathrm{h}^{-1}(\mathrm{C})$. SEM images of electrospun fibers with a core flow rate of with a core flow rate of $0.5 \mathrm{~mL} \cdot \mathrm{h}^{-1}(\mathrm{~B})$ and $1.0 \mathrm{ml} \cdot \mathrm{h}^{-1}(\mathrm{C})$. POM and SEM image scale bars $=25 \mu \mathrm{m}$. 

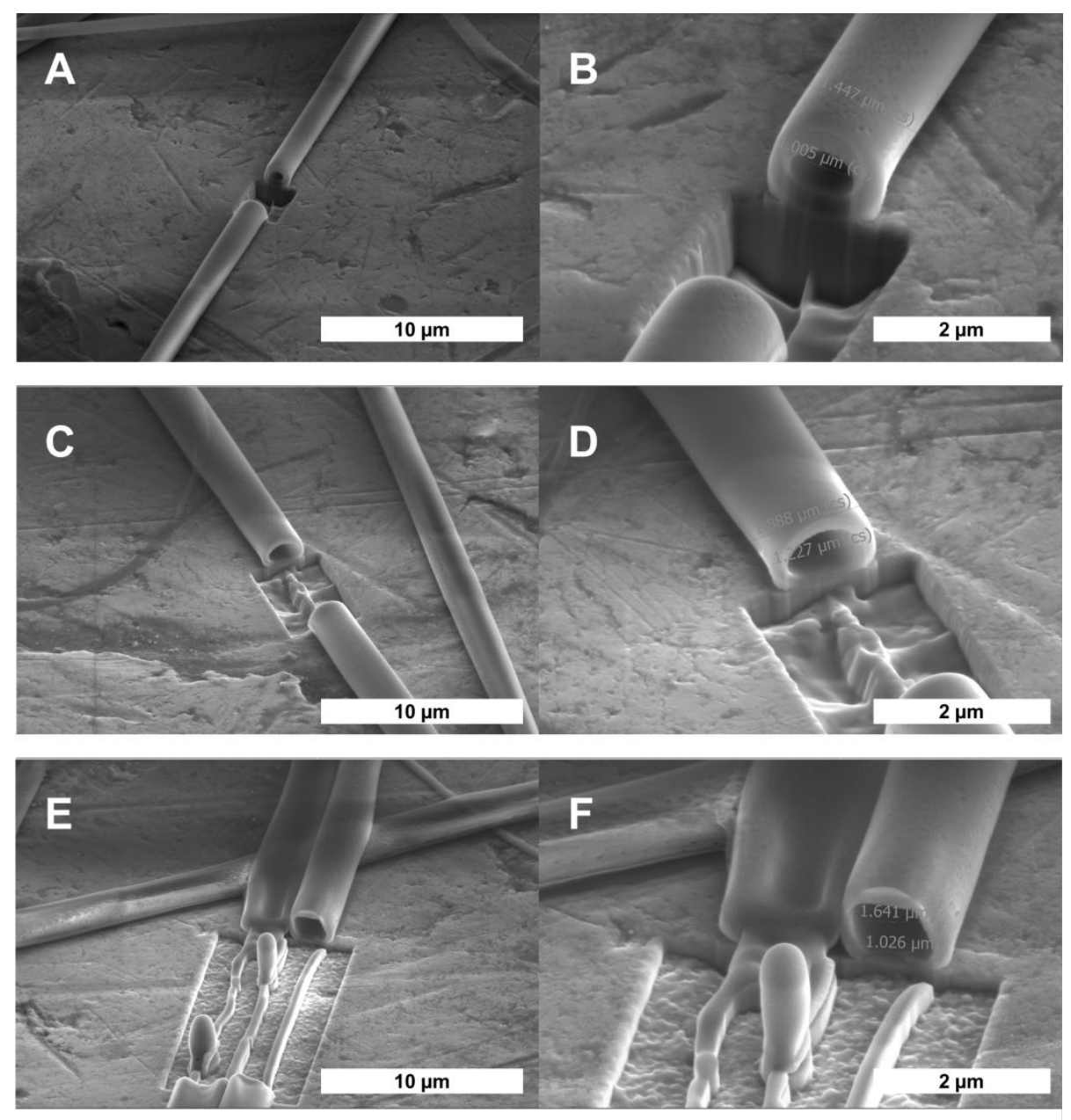

Figure S9: FIB-SEM of 5CB-PVP electrospun fibers w/o surfactant with a core flow rate of $1.0 \mathrm{ml} \cdot \mathrm{h}^{-1}$. 